\title{
Novel Rubber Blends Made from Ultra-Fine Full-Vulcanized Powdered Rubber (UFPR)
}

\author{
Ming TIAN, ${ }^{1}$ Yuan-Wang TANG, ${ }^{1}$ Yong-Lai LU, ${ }^{2}$ \\ Jinliang QIAO, ${ }^{3}$ Tie LI, ${ }^{2}$ and Li-Qun ZHANG ${ }^{1,2,}{ }^{\dagger}$ \\ ${ }^{1}$ Key Laboratory of Beijing City on Preparing and Processing of Novel Polymer Materials, \\ Beijing University of Chemical Technology, Beijing 100029, People's Republic of China \\ ${ }^{2}$ Key Laboratory for Nanomaterials, Ministry of Education, Beijing University of Chemical and Technology, \\ Beijing 100029, People's Republic of China \\ ${ }^{3}$ SINOPEC Beijing Research Institute of Chemical Industry, Beijing 100013, People's Republic of China
}

(Received May 31, 2005; Accepted August 30, 2005; Published January 15, 2006)

\begin{abstract}
Novel ultra-fine full-vulcanized powdered rubber/ethylene-propylene-diene terpolymer (UFPR/ EPDM) blends were firstly prepared by compounding ultra-fine full-vulcanized SBR or NBR particles into EPDM matrix. The morphology and mechanical properties of these novel elastomer blends were investigated. Some unexpected and interesting phenomena were observed. A promising method to prepare elastomer blends with excellent performances was proposed. [DOI 10.1295/polymj.38.50]

KEY WORDS Blends / Rubber / Ultra-Fine Full-Vulcanized Powdered Rubber /
\end{abstract}

Rubber blends have been playing a very important role in rubber industry, where many products, even tires, are made from rubber blends. Rubber blends also demonstrate great interests in academy, which especially involve the morphologies of rubber blends and their effects on the performances. This knowledge is significant for people to know what optimum micro structure of rubber blends should be for the expected performances and how to construct this micro structure. As the same as all the polymer blends, morphology and interface of rubber blends strongly affect their properties, and both of them are determined by many factors. It is the fact that the morphology of the polymer/polymer blend depends on the blend ratio, the viscosity ratio, compatibility between blended polymers, and mixing processing parameters. ${ }^{1,2}$ Traditional method to obtain rubber blends is to blend two or more non-crosslinked bulk rubbers together by mechanical mixing technique in general mixing equipment. The dispersed rubber will experience a complex and gradually dispersing procedure during blending, and the size of dispersed rubber is reduced step by step and is hard to approach $100 \mathrm{~nm}$ or so except the presence of a great compatibility between blended rubbers and a low blend ratio. Additionally, this blending process is time- and energy-consumed due to the high elasticity and high viscosity of rubber. Moreover, phase reverse may occur. i.e., expected dispersion rubber might become continuous phase, when blend ratio of rubber blends is within the range of $0.3: 1-0.8: 1{ }^{3}$ How to get the fine dispersion morphology of rubber blends with a certain controllability of phase and low cost of energy and time is very interesting and valuable not only in industry but also in academy.

After blending rubbers, all kinds of fillers and ingredients will be incorporated into blends and then the blends will be vulcanized. During these procedures, the distribution of ingredients in each rubber phase, crosslinking dynamics of each rubber phase, and the co-crosslinking of interface between two phases are also crucial to the final properties of rubber blends, and even to the final morphology. ${ }^{4,5}$ Controlling the distribution of ingredients in rubber blends and vulcanization of rubber blends is difficult but extremely important, and has a strong relation to the morphology of rubber blends before mixing ingredients, and to the characteristics of each rubber component. ${ }^{6,7}$

Qiao et al. have successfully prepared a series of new ultra-fine full vulcanized powdered rubber (UFPR) by crosslinking rubber latex using irradiation-curing method, including styrene butadiene rubber powder (UFSBRPR), carboxylic styrene butadiene rubber powder (UFCSBRPR), acrylonitrile butadiene rubber powder (UFNBRPR), carboxylic acrylonitrile butadiene rubber powder (UFCNBRPR), silicon rubber powder (UFSiRPR), etc. ${ }^{8-10}$ These UFPR have a size distribution of $50-150 \mathrm{~nm},{ }^{10,11}$ and have been industrialized in China recently. Utilizing these UFPR, some UFPR/thermoplastics blends have been made with good and balanced properties due to the fine dispersion and full vulcanization of rubber phase. ${ }^{8-15}$ If these crosslinked rubber particles with extremely small sizes were blended with other rubbers, the obtained rubber blend would exhibit some advantages

${ }^{\dagger}$ To whom correspondence should be addressed (Tel: 8610-66434860, Fax: 8610-64433964, E-mail: zhanglq@ mail.buct.edu.cn). 
that are very promising for some rubber products, compared with traditional rubber blends. Firstly, the mixing processing would be low-energy consumed and time-efficiency because the interactions between crosslinked rubber particles are much lower than cohesion of bulk rubber. Secondly, the rubber dispersion would be pretty fine domain with the same size as that of UFPR. More importantly, UFPR would keep dispersion phase all the time no matter how high the blend ratio of UFPR to matrix rubber is. Thirdly, the co-crosslinking between two phases would be simplified because one phase has been crosslinked state. Fourthly, all the ingredients could only be mixed into continuous rubber phase because of the crosslinking of dispersed rubber, and as a result, the dispersed rubber phase would keep highly elasticity state, which is very promising for some rubber products. Till now, no related researches have been reported. Ethylene propylene diene terpolymer (EPDM) possesses the balanced heat stability, aging-resistance, elasticity especially at very low temperature, and water resistance, therefore it is now widely applied to many rubber products substituting for natural rubber (NR), styrene butadiene rubber (SBR) and butadiene rubber (BR) etc. In this work, the novel UFPR/EPDM blends were firstly by directly compounding UFSBRPR or UFNBRPR into EPDM matrix. The morphology and mechanical properties of the blends were investigated.

\section{EXPERIMENTAL PART}

\section{Materials}

UFNBRPR, Narpow ${ }^{\mathrm{TM}}$ VP-401 (single particle size distribution, $100-150 \mathrm{~nm}$; ACN content, $26 \mathrm{wt} \%$ ), and UFSBRPR, Narpow ${ }^{\mathrm{TM}}$ VP-101 (average single particle size, $100 \mathrm{~nm}$, molar ratio of styrene/butadiene, $50 / 50$ ), were commercially manufactured by Beijing BHY Chemical Industry New Technology Company, China. EPDM, 4045 (ethylene content, 52 wt \%; ethylidene norbornen (ENB) content, $7.7 \mathrm{wt} \%$, Mooney viscosity at $100^{\circ} \mathrm{C}, 45$ ), was produced by synthetic rubber factory of Jinlin Petroleum Company, China. NBR, N240S (ACN content, 26 wt \%, Mooney viscosity at $\left.100^{\circ} \mathrm{C}, 56\right)$, was bought from JSR Co., Japan. Dicumyl peroxide (DCP) and triallylisocyanurate (TAIC) were available from the chemicals store.

\section{Blends Preparation}

UFPR/EPDM blends were prepared on a two-roll mill. EPDM was firstly masticated, when EPDM becomes soft, UFPR was added into EPDM step by step to ensure good dispersion. Finally, vulcanizing agent (DCP) and accelerator (TAIC) based on EPDM matrix was incorporated (as described in Table I) to get the compound. The compound was vulcanized in hot press with $15 \mathrm{MPa}$ pressure at $160^{\circ} \mathrm{C}$ for the optimum curing time determined by a disk disc oscillating rheometer. Test specimens for mechanical performances were cut from the vulcanized sheets by using dies. The traditional NBR/EPDM blends were also prepared as a counterpart by compounding EPDM with bulk NBR through the above preparation process.

\section{Test and Characterization}

The ultra-thin sections for TEM observations were cut from vulcanizated rubber blends by microtome at about $-100{ }^{\circ} \mathrm{C}$, and then were dyed using $\mathrm{OsO}_{4}$. There was exception for the sections from UFNBRPR/ EPDM blend. The TEM experiments were carried out on an H-800 transmission electron microscope (Hitachi Co., Japan) with an accelerated voltage of $100 \mathrm{kV}$. The temperature dependence of dynamic storage modulus $\left(E^{\prime}\right)$ and loss factor $(\tan \delta)$ was evaluated by using a PE7 dynamic thermal analyzer (DMTA, PE Co., U.S.). The frequency was selected as $10 \mathrm{~Hz}$ and the applied strain was $0.5 \%$. The elevation rate of temperature was set $3{ }^{\circ} \mathrm{C} / \mathrm{min}$. The tensile strength, the stress at $100 \%$ elongation, tear strength and Shore A hardness of the blends were examined according to ASTM D412, ASTM D624 and ASTM D2240, respectively. Curing Properties for UFPR/EPDM blends at $160^{\circ} \mathrm{C}$ were determined by a disk disc oscillating rheometer.

\section{RESULTS AND DISCUSSION}

\section{Morphology of Rubber Blends}

TEM micrographs of UFPR/EPDM and general NBR/EPDM blends are shown in Figure 1. In these TEM micrographs, the deep gray dispersed phase is UFPR or NBR, the light gray continuous phase is EPDM, and the very dark parts are the inorganic fillers as separator to prevent UFPR from aggregating when

Table I. The compositions of the UFPR/EPDM blends

\begin{tabular}{lccccccc}
\hline \multicolumn{1}{c}{ Mixing ratio } & $0 / 100$ & $10 / 90$ & $20 / 80$ & $30 / 70$ & $40 / 60$ & $50 / 50$ & $60 / 40$ \\
\hline EPDM4045(phr) & 100 & 90 & 80 & 70 & 60 & 50 & 40 \\
UFPR(phr) & $/$ & 10 & 20 & 30 & 40 & 50 & 60 \\
DCP(phr) & 5.0 & 4.5 & 4 & 3.5 & 3 & 2.5 & 2.0 \\
TAIC(phr) & 2.0 & 1.8 & 1.6 & 1.4 & 1.2 & 1.0 & 0.8 \\
\hline
\end{tabular}

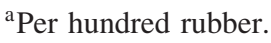




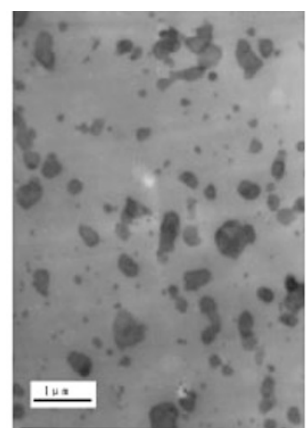

(a) UFSBRPR/EPDM 10/90

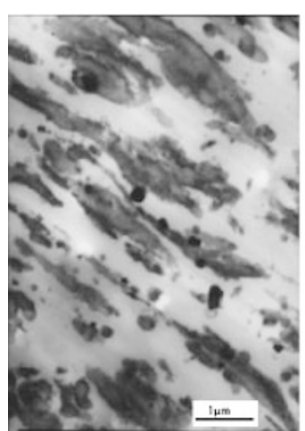

(d) UFSBRPR/EPDM 40/60

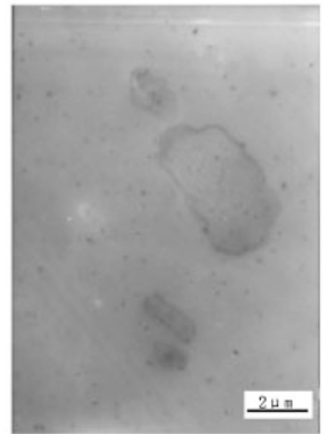

(g) UFNBRPR/EPDM 10/90

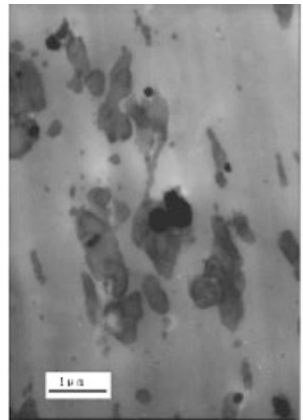

(b) UFSBRPR/EPDM 20/80

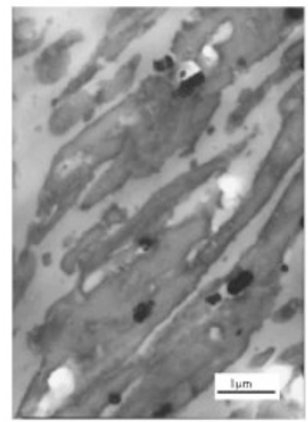

(e) UFSBRPR/EPDM 50/50

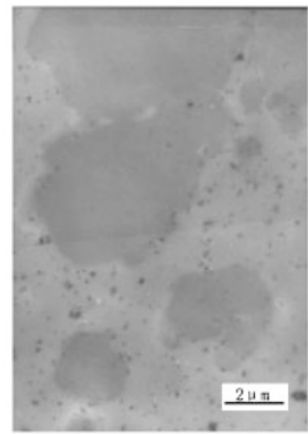

(h) UFNBRPR/EPDM 40/60

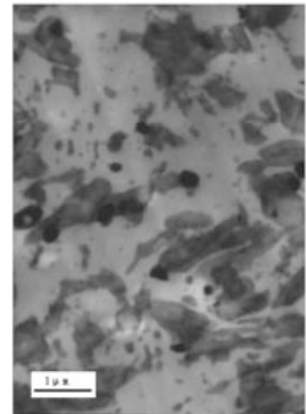

(c) UFSBRPR/EPDM 30/70

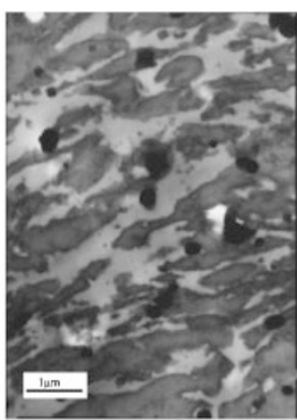

(f) UFSBRPR/EPDM 60/40

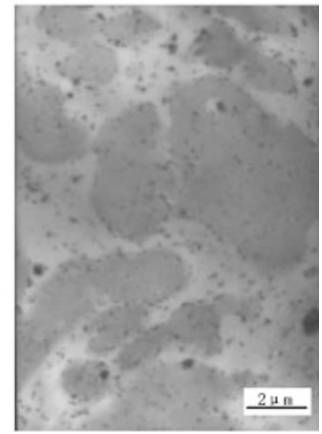

(i) UFNBRPR/EPDM 60/40

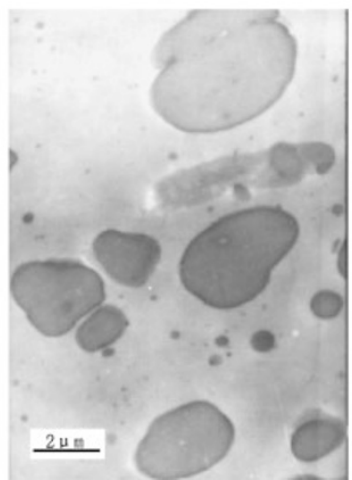

(j) NBR/EPDM 20/80

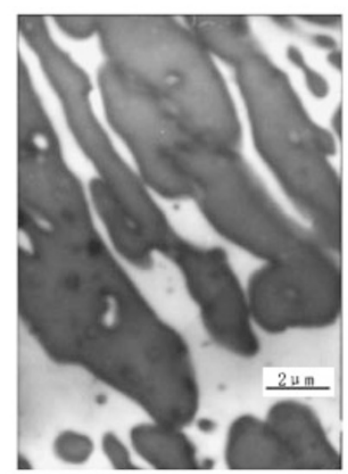

(k) NBR/EPDM 60/40

Figure 1. TEM images of UFPR/EPDM and NBR/EPDM blends.

drying UFPR, whose sizes and types are different depending on the type of UFPR. Figures 1a-f, corresponding to UFSBRPR/EPDM blends, clearly present that all the blends exhibit the typical "sea-island" morphology under investigated range of blend ratio of UFSBRPR to EPDM. No phase reverse is observed even when the blend ratio of UFSBRPR to EPDM reaches $60 / 40$. It is also found that when the blend ratio of UFSBRPR/EPDM is 10/90, UFSBRPR is finely and uniformly dispersed in EPDM as spherical particles with the size close to its original particle size, about $200 \mathrm{~nm}$. However, as the blend ratio of UFSBRPR to EPDM increases, the UFSBRPR particles start to agglomerate. Correspondingly, the size 
Table II. Curing Properties for UFPR/EPDM blends at $160^{\circ} \mathrm{C}$

\begin{tabular}{|c|c|c|c|c|c|c|c|}
\hline \multirow{2}{*}{ Blend ratio (UFPR/EPDM) } & $0 / 100$ & $10 / 90$ & $20 / 80$ & $30 / 70$ & $40 / 60$ & $50 / 50$ & $60 / 40$ \\
\hline & \multicolumn{7}{|c|}{ UFSBRPR/EPDM blends } \\
\hline$M_{\min }(\mathrm{dN} \cdot \mathrm{m})^{\mathrm{a}}$ & 5.0 & 4.9 & 5.1 & 5.5 & 6.0 & 6.3 & 6.8 \\
\hline$M_{\max }(\mathrm{dN} . \mathrm{m})^{\mathrm{b}}$ & 59.2 & 54.5 & 50.2 & 46.7 & 44.9 & 40.8 & 36.9 \\
\hline$\Delta M(\mathrm{dN} \cdot \mathrm{m})^{\mathrm{c}}$ & 54.2 & 49.6 & 45.1 & 41.2 & 38.9 & 34.5 & 30.1 \\
\hline \multirow[t]{2}{*}{$T_{90}(\min )^{\mathrm{d}}$} & 32.2 & 37.2 & 35.4 & 34.5 & 34.4 & 39.7 & 40.4 \\
\hline & \multicolumn{7}{|c|}{ UFNBRPR/EPDM blends } \\
\hline$M_{\min }(\mathrm{dN} . \mathrm{m})$ & 5.0 & 5.6 & 7.0 & 7.5 & 8.0 & 8.4 & 8.6 \\
\hline$M_{\max }(\mathrm{dN} . \mathrm{m})$ & 59.2 & 59.0 & 61.9 & 61.5 & 61.3 & 59.3 & 58.3 \\
\hline$\Delta M(\mathrm{dN} . \mathrm{m})$ & 54.2 & 53.4 & 54.9 & 54.0 & 54.0 & 51.3 & 49.7 \\
\hline$T_{90}(\min )$ & 32.2 & 31.0 & 30.2 & 30.7 & 30.1 & 30.7 & 32.6 \\
\hline
\end{tabular}

${ }^{\mathrm{a}}$ The minimum torque. ${ }^{\mathrm{b}}$ The maximum torque. ${ }^{\mathrm{c}}$ The difference between maximum and minimum torque.

${ }^{\mathrm{e}}$ The time required for $90 \%$ cross-linking.

of dispersion becomes larger and larger, and the shape of dispersion evolves into strip from sphere. Similar "sea-island" morphology can be observed in UFNBRPR/EPDM blends, as shown in Figures 1g-i. Compared with UFSBRPR/EPDM blends, the dispersion of UFNBRPR in EPDM is bad, and it is always dispersed as spherical particles of $1-5 \mu \mathrm{m}$ in EPDM, which is much larger than its original size, whatever the UFNBRPR/EPDM blend ratio is. The TEM images of NBR/EPDM blends prepared by compounding bulk NBR and EPDM, as shown in Figures $1 \mathrm{j}-\mathrm{k}$, demonstrate that bulk NBR are dispersed into spherical particles with the average size of $2 \mu \mathrm{m}$ in EPDM when NBR/EPDM ratio is 20/80, whereas a close co-continuous phase morphology with very large domain sizes of NBR and EPDM forms when the NBR/ EPDM ratio reaches 60/40. These results demonstrate that the phase reversion in UFPR/EPDM blends does not happen regardless of the blend ratio, which is the advantage of this novel rubber blends. However, the dimension and shape of dispersion are still strongly dependent on the features of UFPR though the UFPR possesses the potentials of being the very fine dispersion phase. UFPR has been vulcanized before being incorporated into rubber, so that the dispersion behavior of them should be somewhat similar to that of inorganic fillers. In this type system, the filler-filler interaction and filler-rubber interaction predominate the dispersion and aggregation of UFPR besides the processing parameters, filler characteristics, and loading of filler. Therefore, authors assumed that there might be three mainly reasons for this phenomenon. (1) Compared with the inorganic fine particles, the filler-filler interaction of UFPR is stronger because of the entanglement of those rubber macromolecules with free segments located in surface regions of UFPR. (2) The lower modulus and good deformability of UFPR particles also impair dispersing because the higher shear force around UFPR particles agglomera- tions could not be generated according to traditional stress transfer theory. ${ }^{16}$ These two reasons are disadvantageous of dispersion of UFPR in rubber matrix. (3) The filler-rubber interaction (i.e., the compatibility between UFPR and matrix rubber) is still essential for the morphology of this kind blends. In UFNBRPR/ EPDM system, between which great difference in polarity exists, the fine dispersion of UFPR cannot be achieved even though in the case of low blend ratio. Therefore, authors suggested that following methods might further improve the dispersion of UFPR. (1) Improving cross-linking density of UFPR might increase the modulus of UFPR and decrease the filler-filler (UFPR-UFPR) interaction. (2) Increasing the amount of separator might further avoid the contact between UFPR. (3) Incorporating some compatibilizer into UFPR/rubber blends can enhance the filler (UFPR)rubber interactions.

\section{Curing Kinetics of UFPR/Rubber Blends}

Table II shows the influence of the blend composition on curing kinetics of UFPR/rubber blends. In UFSBRPR/EPDM system, the difference between $M_{\max }$ and $M_{\min }(\Delta M)$ obviously decreases with increasing of UFSBRPR fraction. The value of $\Delta M$ was generally suggested to be proportional to the final number of cross-links. ${ }^{17,18}$ Therefore, it was deduced that UFSBRPR noticeably decreased the cross-linking density of EPDM. These results should be attributed to relative high reactivity of SBR with peroxide, which caused that considerable amount of peroxide curing agents were extracted from EPDM phase to UFSBRPR to react with SBR during curing. On the other hand, the influence of UFNBRPR on the curing kinetics of EPDM is much less than that of UFSBRPR, and could be observed only when the content is beyond $50 \%$. These results might be due to NBR's low reactivity with peroxide in relation to SBR. 

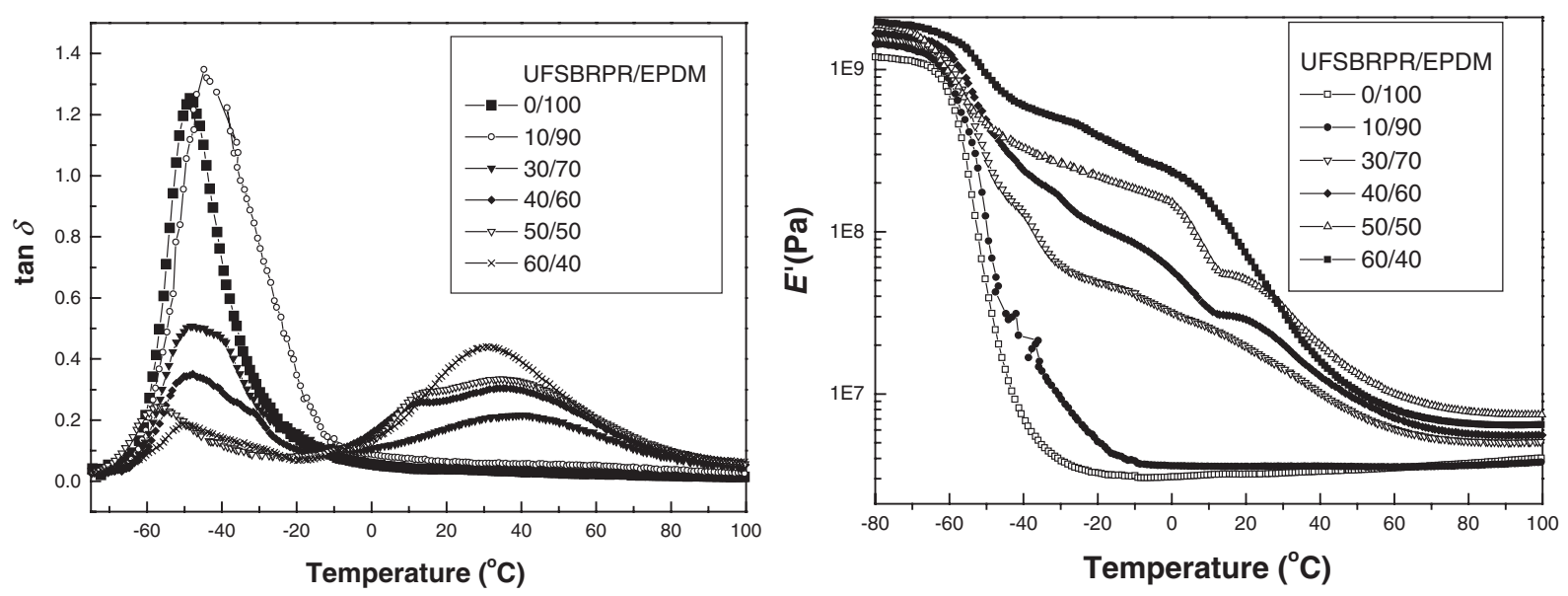

(a) UFSBRPR/EPDM
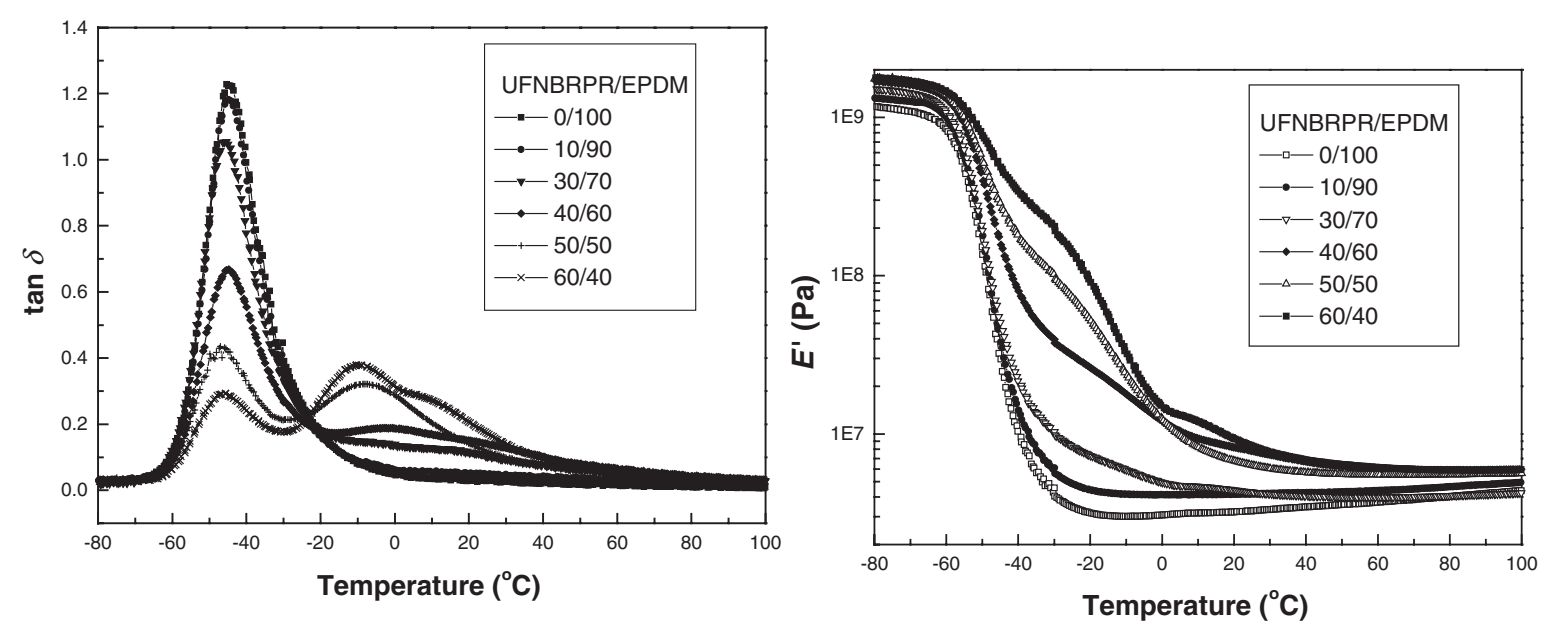

(b) UFNBRPR/EPDM

Figure 2. The temperature dependence of loss factor $(\tan \delta)$ and dynamic storage modulus $\left(E^{\prime}\right)$ of UFPR/EPDM blends.

\section{DMTA Analysis on Rubber Blends}

DMTA analyses were performed in the cured pure EPDM and UFPR/EPDM blends. Figure 2 displays the temperature dependence of loss factor $(\tan \delta)$ and dynamic storage modulus $\left(E^{\prime}\right)$ of UFPR/EPDM blends (vulcanizates). The temperature where the peak of loss factor $(\tan \delta)$ appears is regarded as the glass transition temperature $\left(T_{\mathrm{g}}\right)$ for polymer. It can be seen that only one peak of $\tan \delta$ for pure EPDM appears, which locates at $-50^{\circ} \mathrm{C}$ or so, corresponding to the $T_{\mathrm{g}}$ of crosslinked EPDM. When the blend ratio of UFSBRPR/ EPDM is $10 / 90$, the $T_{\mathrm{g}}$ of crosslinked EPDM shifts to $-45^{\circ} \mathrm{C}$ though only one peak of $\tan \delta$ for the blend appears. This implies that the fine dispersed UFSBRPR play a remarkable role on the immobility of EPDM macromolecules. Hereafter, another peak of $\tan \delta$ around $30^{\circ} \mathrm{C}$ or so begins to emerge, moreover, its peak height increases with the blend ratio of UFSBRPR/EPDM increasing. This peak at $30^{\circ} \mathrm{C}$ is the reflection of glass transition of UFSBRPR. Apparently, the $T_{\mathrm{g}}$ of UFSBRPR is higher than that of general SBR, which is around $-52{ }^{\circ} \mathrm{C}^{19}$ (tested by DMTA). This is ascribed to the higher content of styrene in UFSBRPR (i.e. 50\%), whereas the styrene weight content of general SBR is well known as $23.5 \%$. When the content of UFSBRPR is beyond $30 \%$, two shoulders appear in the $\tan \delta$ curve at hightemperature side of low-temperature $\tan \delta$ peak and low-temperature side of high-temperature $\tan \delta$ peak. Corresponding multiple transitions can be observed in the storage modulus curve. The phenomena demonstrate that there are some interfacial phase and cocrosslinking between EPDM matrix and UFSBRPR. The storage modulus of UFSBRPR/EPDM blends, shown in Figure 2a, expresses that the blending of UFSBRPR and EPDM raises the temperature at which EPDM modulus decays. It also can be seen that, as the increasing of UFSBRPR/EPDM ratio, dynamic stor- 

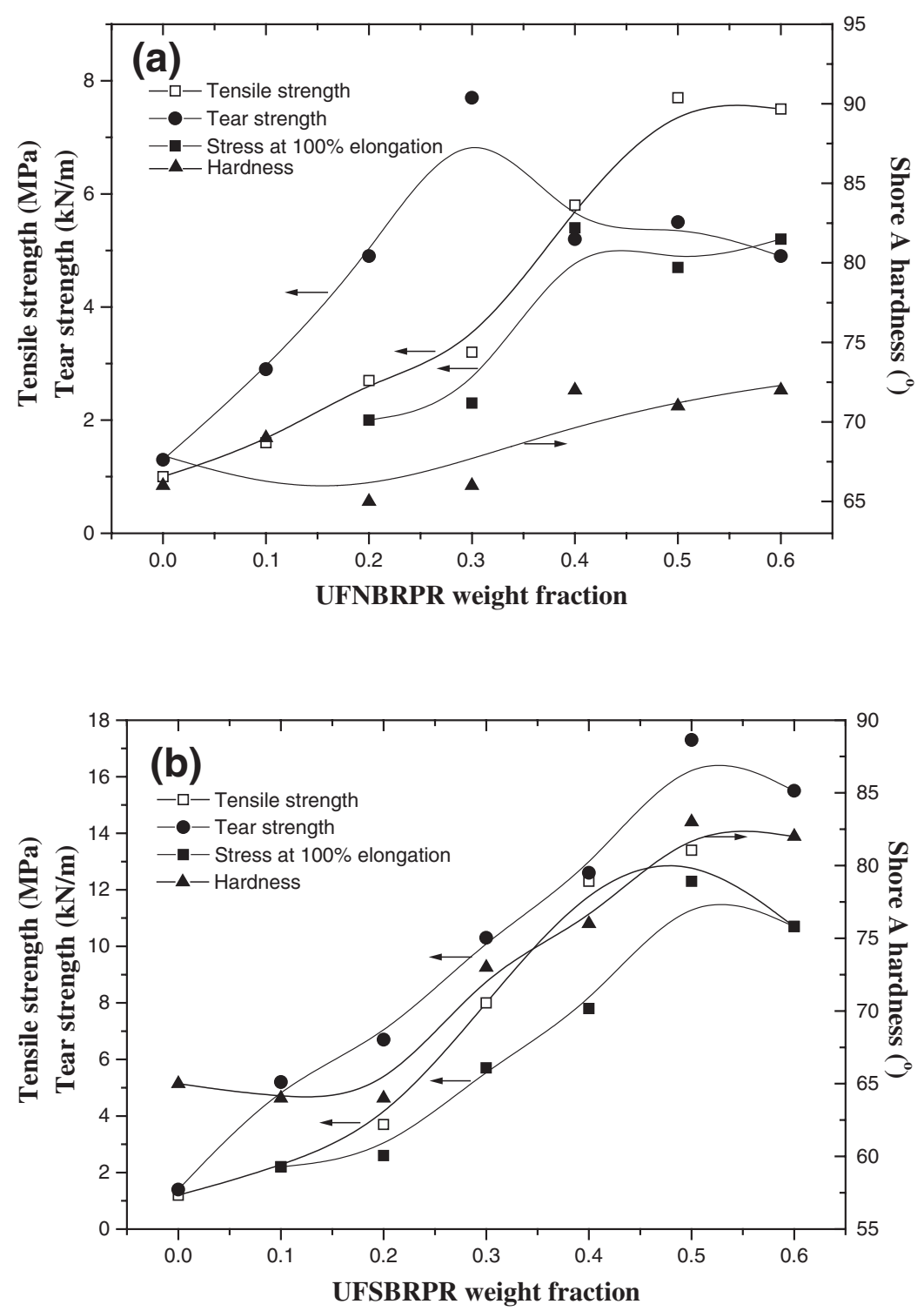

Figure 3. Mechanical properties of (a) UFNBRPR/EPDM and (b) UFSBRPR/EPDM blends.

age modulus $\left(E^{\prime}\right)$ of the UFSBRPR/EPDM blend increases not only at the temperature below $T_{\mathrm{g}}$ of EPDM but also at the temperature below $T_{\mathrm{g}}$ of UFSBRPR. Consequently, UFSBRPR demonstrates a distinct reinforcement to EPDM. The higher modulus of UFSBRPR dispersed in EPDM and a certain of interfacial interaction are mainly responsible for this reinforcement. Similar DMTA results for UFNBRPR/ EPDM blends are found in Figure $2 \mathrm{~b}$, where $T_{\mathrm{g}}$ of dispersed UFNBRPR is around $-10^{\circ} \mathrm{C}$. The increase in dynamic storage modulus $\left(E^{\prime}\right)$ of the blend with the increasing of UFNBRPR content still lies in that UFNBRPR has higher stiffness due to its higher molecular polarity. However, it should be point out that the DMTA behavior of UFNBRPR/EPDM blend is much simpler than that of UFSBRPR/EPDM one. In most compositions, there are no other transitions be- sides two main transitions corresponding to EPDM phase and UFPR. This result implies that the interfacial interaction between EPDM and UFNBRPR is less strong compared with that between EPDM and UFSBRPR.

\section{Mechanical Properties of Rubber Blends}

Figure 3 displays that UFPR (i.e., elastomeric filler) possesses the notable reinforcement to matrix rubber, which is out of our expectation and interesting. This is illustrated by the increasing stress at $100 \%$ elongation with the increasing UFPR loading. However, some blends don't exhibit the stress at $100 \%$ elongation because of their very low elongations. As shown in Figure $3 \mathrm{a}$, as the blend ratio of UFNBRPR/EPDM increases, the blend exhibits a marked enhancement in hardness and tensile strength, and tear strength 
of the blend appears a maximum value at the UFNBRPR/EPDM ratio of 30/70. Compared with UFNBRPR, UFSBRPR shows the more remarkable reinforcement to EPDM as observed in Figure 3b, which is possibly attributed to higher modulus and better dispersion of UFSBRPR, and stronger interaction between UFSBRPR and EPDM. It is well known that the dispersion, interfacial interaction and loading of filler etc. mainly govern the reinforcement of filler to rubber. The dispersion of UFPR is not as good as that of fine inorganic filler, and the modulus of UFPR is also far lower than that of inorganic filler, both of which are detrimental to reinforcement. Consequently, the interfacial co-crosslinking produced in vulcanization might be responsible for the reinforcement effect of UFPR. Furthermore, the deformation of UFPR filler during tension was also another possible reason because it could alleviate the interface stress concentration and induce the orientation of matrix rubber macromolecules. Unlike hard inorganic filler, elastomeric filler probably have a good balance among elasticity, hardness, and tensile strength, etc. The further research about it is valuable and necessary.

\section{CONCLUSIONS}

Novel UFPR/EPDM blends were firstly prepared by compounding ultra-fine full-vulcanized SBR or NBR particles into EPDM matrix. Different from traditional bulk rubber blends, no matter how high the blend ratio of UFPR to EPDM matrix is, UFPR particles always keep being dispersion phase due to its crosslinking state. Although the UFPR possesses the potentials to be the very fine dispersion phase, the strong filler-filler interaction effect of UFPR and the lower modulus ratio of filler to rubber hinder UFPR from getting fine dispersion. DMTA and mechanical properties test surprisingly demonstrate the prominent reinforcement effect of UFPR to rubber matrix. It is believed by authors that the special morphology of UFPR/rubber blends and the mechanism for reinforcing effect of UFPR are very valuable and deserve to be deeply and further studied.
Acknowledgment. The authors thank Key Project Plan of Natural Science Foundation of Beijing City (Grant No. 2031001) as well as National Natural Science Foundation (Grant No. 50503003) for financial support.

\section{REFERENCES}

1. D. R. Paul and C. B. Bucknall, "Polymer Blend," John Wiley \& Sons Inc., New York, 2000, Vol. 1, p 501.

2. T. K. Kang, Y. Kim, and W. K. Lee, et al., J. Appl. Polym. Sci., 72, 989 (1999).

3. D. Romanini, E. Garagnani, and E. Marchetti, New Polymeric Materials: Reactive Processing and Physical Properties; Proceedings of the International Seminar, Naples, Italy, 9-13 June, 1986.

4. J. E. Callan, W. M. Hess, and C. E. Scott, Rubber Chem. Technol., 44, 814 (1971).

5. G. Cotton and L. J. Murphy, Rubber Chem. Technol., 61, 609 (1988).

6. V. A. Shershnev, Rubber Chem. Technol., 66, 985 (1982).

7. A. Y. Coran, Rubber Chem. Technol., 61, 281 (1979).

8. M. Zhang, Y. Liu, and X. Zhang, et al., Polymer, 43, 5133 (2002).

9. F. Huang, Y. Liu, and X. Zhang, et al., Macromol. Rapid Commun., 23, 786 (2002).

10. J. L. Qiao, G. S. Wei, and X. H. Zhang, et al., U.S., Patent 6,423,760 (2002).

11. Y. Liu, X. Zhang, and G. Wei, et al., Chin. J. Polym. Sci., 20, 93 (2002).

12. J. Peng, J. Qiao, and S. Zhang, et al., Macromol. Mater. Eng., 287, 867 (2002).

13. J. Peng, X. Zhang, and J. Qiao, et al., J. Appl. Polym. Sci., 86, 3040 (2002).

14. Y. Liu, X. Zhang, and J. Gao, et al., Polymer, 45, 275 (2004).

15. X. Zhang, Y. Liu, and J. Gao, et al., Polymer, 45, 6959 (2004).

16. H. L. Cox, Brit. J. Appl. Phys., 3, 72 (1952).

17. G. R. Cotton, Rubber Chem. Technol., 45, 29 (1972).

18. C. E. Decker, R. W. Wise, and D. Cuerry, Rubber Chem. Technol., 36, 451 (1963).

19. S. Z. Xie, D. X. Liu, and M. L. Zhou, "Handbook of Rubber Industry," chap. 1, Chemical Industry Press, (Beijing) China, 1989, p 116. 